\title{
“COROA MORTAL": ANATOMIA E IMPORTÂNCIA NAS HERNIORRAFIAS INGUINAIS
}

\section{“MORTAL CROWN": ANATOMY AND IMPORTANCE TO INGUINAL HERNIORRHAPHIES}

\author{
Luiz Carlos Buarque de Gusmão, TCBC $-\mathrm{AL}^{1}$ \\ Thiago Fortes Pinto Cavalcanti ${ }^{2}$ \\ Renato Wendell Ferreira Damasceno ${ }^{2}$ \\ Antônio José Casado Ramalho ${ }^{3}$ \\ Jacqueline Silva Brito Lima ${ }^{4}$
}

\begin{abstract}
RESUMO: Objetivo: O presente estudo visa a fornecer dados anatômicos sobre a incidência, a origem, e o trajeto da artéria que transita pela parede posterior do canal inguinal, permitindo evitar acidentes durante as intervenções cirúrgicas na região inguinal. Método: Os autores realizaram a dissecação de 40 regiões inguinais de cadáveres fixados. Resultados: Em 38 casos (95\%) existia uma artéria, às vezes, de calibre insignificante, que estava presente posteriormente ao canal inguinal. Em 27/38 casos (67,5\%), esta artéria representava a "coroa mortal", pois era constituída pela origem anômala da artéria obturatória, na artéria epigástrica inferior, ou representava uma anastomose da artéria epigástrica inferior com a artéria obturatória. Nos 11/38 casos restantes $(27,5 \%)$, existia uma artéria, de reduzido calibre, que tinha origem na artéria epigástrica inferior, e capilarizava-se, após curto trajeto na parede posterior do canal inguinal. Conclusão: A existência da "coroa mortal", situada posteriormente ao canal inguinal, sempre implica em risco de hemorragias nas herniorrafias inguinais.
\end{abstract}

Descritores: Hérnia inguinal; Abdome; Cirurgia; Anatomia regional.

\section{INTRODUÇÃO}

Os vários procedimentos para correção de hérnias inguinais defrontam-se, ainda hoje, com uma série de dificuldades técnicas, o que leva a um índice considerável de recidivas. Por outro lado, o avanço irreversível das correções herniárias por videolaparoscopia tem levado cada dia mais a uma busca de um melhor conhecimento anatômico da região inguinal.

Vários acidentes vasculares são descritos na literatura durante a abordagem do saco herniário e durante o reforço da parede posterior do canal inguinal. Entre os acidentes vasculares descritos na literatura, está a secção completa ou a transfixação de uma artéria existente na parede posterior do canal inguinal ${ }^{1,2}$. Essa artéria é ramo da artéria epigástrica inferior e se anastomosa com a artéria obturatória ${ }^{3,4-8}$ ou pode ser a própria origem da artéria obturatória ${ }^{9-15}$, ou seja, uma artéria obturatória aberrante que se origina da artéria epigástrica inferior e segue em direção ao canal obturatório, passando antes por trás do canal inguinal e pela borda medial do anel femoral ${ }^{16}$. Essa anastomose é denominada "Coroa Mortal" pe-

1. Professor do Departamento de Morfologia da Universidade Federal de Alagoas; Mestre e Doutor em Anatomia Humana pela Escola Paulista de Medicina.

2. Monitores da Disciplina de Anatomia Humana da Universidade Federal de Alagoas.

3. Professor do Departamento de Morfologia da Universidade Federal de Alagoas; Especialista em Anatomia Humana.

4. Professora do Departamento de Morfologia da Universidade Federal de Alagoas; Mestre em Anatomia Humana.

Trabalho realizado no Departamento de Morfologia da Universidade Federal de Alagoas com financiamento da Fundação de Amparo à Pesquisa do Estado de Alagoas e do CNPq. 
las grandes hemorragias que acarreta e que podem levar à morte do paciente ${ }^{3}$.

Objetivo da pesquisa é dirimir dúvidas e esclarecer dados a respeito da incidência, origem e principalmente trajeto deste vaso, buscando prevenir os acidentes vasculares durantes as herniorrafias inguinais.

\section{MÉTODO}

Cumprindo o que determina a Lei Federal $\mathrm{n}^{\circ} 8.501$, de 30 de novembro de 1992, e após aprovação institucional, foram utilizadas 40 regiões inguinais de cadáveres adultos, fixados, de ambos os sexos e de diferentes raças, pertencentes à Universidade Federal de Alagoas e à Escola de Ciências Médicas.

A dissecação buscou informações sobre a presença de vasos arteriais na parede posterior do canal inguinal, analisando sua origem, seu trajeto e sua incidência.

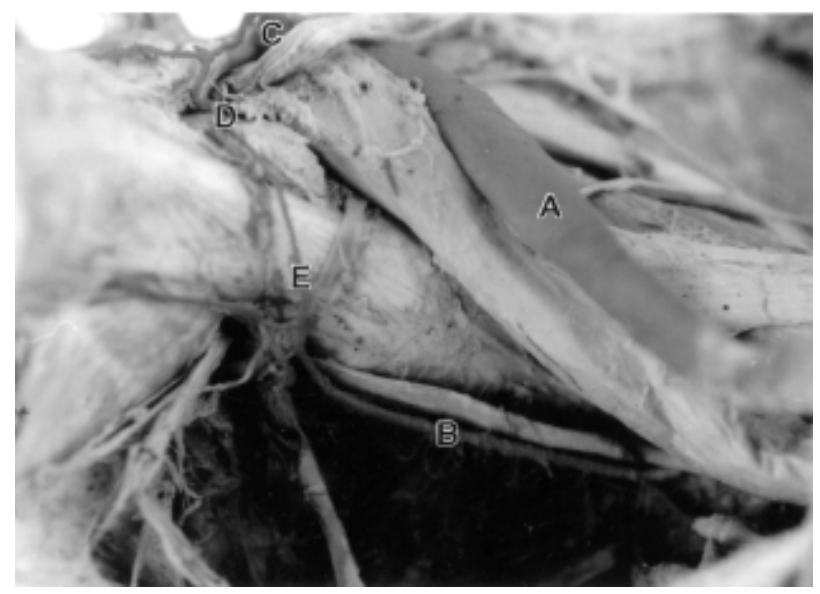

Figura 1 - Região inguinal direita: A - artéria ilíaca externa; $B$ - artéria obturatória; $C$ - funículo espermático; $D$ - "Coroa Mortal”; E- anastomose com a artéria obturatória.

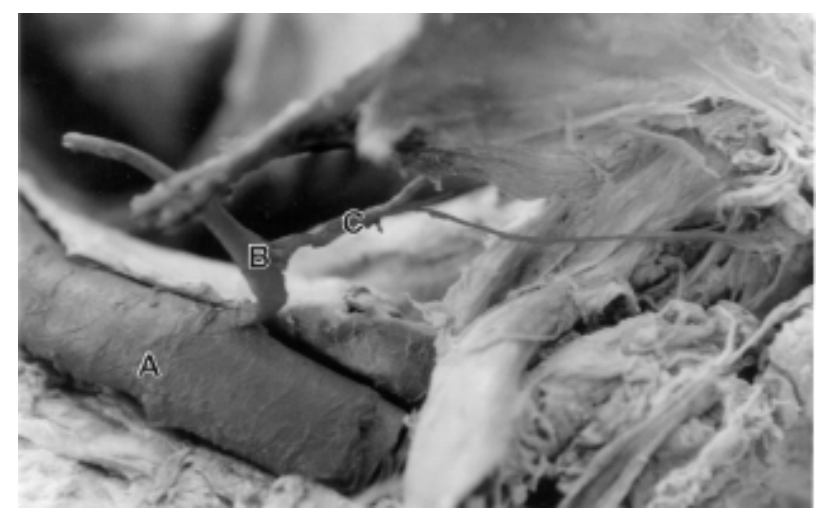

Figura 3 - Região inguinal esquerda: A - artéria ilíaca externa; $B$ - arteria epigástrica inferior; $C$ - "Coroa Mortal".

\section{RESULTADOS}

Das 40 regiões inguinais dissecadas, em 38 delas $(95 \%)$, foi observado a presença de uma artéria, às vezes de reduzido calibre, transitando posteriormente ao canal inguinal (Figuras 1, 2 e 3). Em 14 casos $(35 \%)$, houve origem de dois ramos, sendo um ramo da artéria epigástrica inferior e outro originário da artéria obturatória. Esses dois ramos anastomosavam-se na face pélvica do púbis, constituindo a "coroa mortal" (Figura 1). Em 13 casos $(32,5 \%)$, a "coroa mortal'era a própria artéria obturatória, que teve origem anômala da artéria epigástrica inferior, e que após passar por trás do canal inguinal, seguiu em direção ao canal obturatório (Figura 2). Finalmente, em 11 casos (27,5\%), o vaso em questão saía da face medial da artéria epigástrica inferior, e após curto trajeto na parede posterior do canal inguinal, capilarizava-se sobre o púbis e o anel femoral (Figura 3).

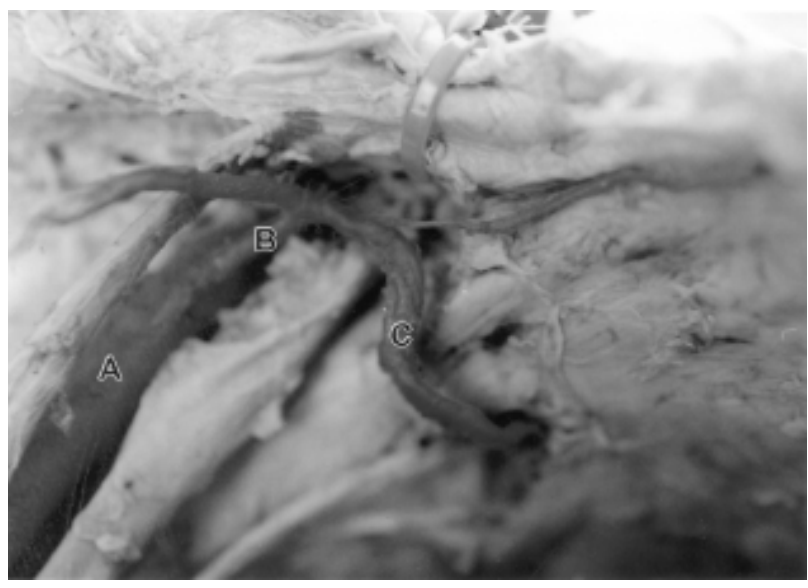

Figura 2 - Região inguinal esquerda: $A$ - artéria ilíaca externa; $B$ - artéria epigástrica inferior; $C$ - artéria obturatória anômala ("Coroa Mortal").

\section{DISCUSSÃO}

A presença de um vaso arterial na parede posterior do canal inguinal, observado em $95 \%$ dos casos, é um dado importante que deve ser levado em conta durante a realização de herniorrafias inguinais.

A "Coroa Mortal" é referida na literatura como a anastomose entre a artéria epigástrica inferior e a artéria obturatória, ou a própria origem aberrante da artéria obturatória a partir da artéria epigástrica inferior.

A origem da artéria obturatória da artéria epigástrica inferior foi observada em $32,5 \%$ dos ca- 
sos, o que contraria a literatura ${ }^{2,4,11-16}$, que fornece uma frequiência de $20 \%$. A anastomose da artéria epigástrica inferior com a artéria obturatória foi detectada em $35 \%$ dos casos, fato que contraria os dados encontrados na literatura pesquisada ${ }^{3}$, quando informa um resultado de $10 \%$.

Portanto, a presença da "Coroa Mortal" foi evidenciada em $67,5 \%$ das dissecções. Os casos restantes $(28,5 \%)$, em que existia um ramo originário da artéria epigástrica inferior, posteriormente ao canal inguinal, não acreditamos que, devido ao seu reduzido calibre, possa produzir hemorragias que sejam tão importantes como aquelas decorrentes da lesão da "Coroa Mortal".

Quanto ao trajeto, a artéria obturatória aberrante tinha um trajeto em direção ao canal obturatório, passando por trás do canal inguinal e pela face pélvica do púbis, sendo essa a descrição relatada pela literatura pesquisada ${ }^{16}$. Por outro lado, o ramo púbico da artéria epigástrica inferior, após passar pela parede posterior do canal inguinal, tinha trajeto na parte superior do púbis em direção ao anel femoral, para depois descer pela borda medial do anel femoral e anastomosarse com o ramo púbico da artéria obturatória, sendo esse achado igual ao citado na literatura pesquisada ${ }^{6-10}$.

Concluimos que, a presença de vasos na parede posterior do canal inguinal, que podem ou não representar a anastomose entre a artéria epigástrica e a artéria obturatória, sempre implica em risco nas herniorrafias inguinais.

\begin{abstract}
Background: The present study shows the anatomical aspects, the incidence, the origin and the location of the artery that transits through the posterior wall of inguinal canal, allowing the avoidance of accidents during the surgeon interventions in this region.Methods: The authors performed dissection of 40 inguinal regions in cadavers.Results: In 33 cases (95\%) there was an artery, occasionaly, of insignificant caliber, that was present in the posterior inguinal canal. In 27/38 cases (67.5\%), this artery represented the "Mortal Crown", as constituted by an anomalous origin of the obturatory artery emerging from the inferior epigstric artery or because of its anastomosis between the inferior epigastric artery and the obturatory artery. In the remaining $11 / 38$ cases (27.5\%), there was an artery of a reduced caliber, which emerged from the inferior epigastric artery, with a short tract on the posterior wall of the inguinal canal. Conclusion: The existence of the "Mortal Crown", on the posterior wall of the inguinal canal, always implicates risks at the inguinal herniorrhaphy.
\end{abstract}

Key Words: Hernia, inguinal; Abdomen; Surgery; Anatomy, regional.

\section{REFERÊNCIAS}

1. Schaeffer JP - Human Anatomy. New York-McGrawHill Book Company, 1942.

2. Quénu J, Loygue J, Perrotin J, et al - Intervenciones sobre la parede abdominal y el tubo digestivo. Barcelona - Masson, 1968.

3. Davis L - Clínica Cirúrgica. Rio de Janeiro - Guanabara Koogan, 1961.

4. Balli R, Bertelli D, Bruni AC, et al - Trattato di Anatomia Umana. Milão - Casa Editrice, 1932.

5. Chiarugi G - Istituzione di Anatomia Del'Uomo. Milão - Società Editrice Libraria, 1936.

6. Romanes GJ - Manual de Anatomia Prática. São Paulo -Atheneu, 1976.

7. Kahle W, Leonhardt H, Platzer W - Atlas de Anatomia Humana. São Paulo-Atheneu, 1988.

8. Moore KL - Anatomia Orientada para a Clínica. Rio de Janeiro - Guanabara Koogan, 1994.
9. Mello JB, Moraes IN, Nahas P - Residente de Cirurgia. São Paulo - Roca, 1992.

10. Giuliano A - Clínica y Terapêutica Quirúrgica. Buenos Aires - El Ateneo, 1966.

11. Testut L, Latarjet A - Tratado de Anatomia Humana. Barcelona-Salvat, 1975.

12. Woodburne RT - Anatomia Humana. São Paulo Guanabara Koogan, 1984.

13. Lex A, Valtorta A - Hérnia: Aspecto Clínico e Cirúrgico. São Paulo - Panamed, 1984.

14. Lockhart RD, Hamilton GF, Fyfe FW - Anatomia Humana. Cidade do México - Editorial Interamericana, 1965.

15. Gardner Ernest, et al - Anatomia. Rio de Janeiro Guanabara Koogan, 1988.

16. Latarjet M, Liard AR -Anatomia Humana. São Paulo Panamericana, 1993.

Endereço para correspondência:

Luiz Carlos Buarque de Gusmão

Rua Santa Júlia, 228 - Farol - CEP: 57055-550 - Maceió - AL 